\title{
TREATMENT OF ACUTE POISONING
}

SIR-I find the advice given by Lieutenant-Colonel T. B. Stephens on the treatment of opiate poisoning (Stephens 1973) to be misleading. As the correct emergency treatment of this poisoning is a life-saving procedure, it is one with which all doctors.who deal with poisoned patients should be familiar.

This is one of the few poisonings for which there is a specific antidote available and the efficacy of this antidote, the opiate antagonist, depends upon it being used adequately. In " severe cases" an intravenous dose of 3 to $5 \mathrm{mg}$ of Nalorphine will have little or no effect, and the correct initial dose should be 10 to $15 \mathrm{mg}$ intravenously repeated every 15 minutes until consciousness is regained and respiration returns to normal. In very severe poisonings even higher doses can be given (Mathew and Lawson 1970). As the action of the Nalorphine is generally shorter lasting than that of the opiate taken, repeated doses may have to be given to prevent the recurrence of intoxication. Deterioration can be rapid, and severely poisoned patients should be kept under observation - in some cases for as long as 48 hours after apparent recovery. A new specific opiate antagonist Naloxone H.C.1 (Narcam) will soon be available, which has advantages over Nalorphine and Levallorphan in that it has no intrinsic respiratory depressant action and also, unlike other antagonists, readily reverses the effects of Pentazocine (Evans et al 1973).

\section{I am, etc.,}

\section{E. J. EVANS}

\section{Montague Avenue,}

Gosforth, Newcastle-upon-Tyne.

20 March, 1973.

\section{REFERENCES}

Evans, L. E. J., Roscoe, P., Swainson, C. P. and Prescot, L. F. (1973). Lancet i, 452.

Matthew, H. and Lawson, A. A. H. (1970). Treatment of Common Acute Poisonings. E. \& S. Livingstone Ltd. Edinburgh.

Stephens, T. B. (1973). J. roy. Army med. Cps. 119, 22.

\section{BOOK REVIEWS}

Textbook of Surgery. Third ed. Ed. by D. A. MacFarLane and L. P. Thomas. Edinburgh and London. Churchill Livingstone. 1972. Pp. xi $+764 . £ 4 \cdot 00$. Illustrated.

This book is written to fulfil the needs of the undergraduate surgical student and it achieves its object in a most commendable way. By-passing that which is obstruse it omits nothing of importance and covers the main-stream material of surgery in a clear, logical and comprehensive manner. The illustrations are all line and shade drawings which are easy to follow and to remember. Each chapter concludes with a limited number of suggestions for further reading but these are carefully chosen to satisfy the most urgent thirst for knowledge.

This book will not meet the requirements of the postgraduate, but it is a very good basis for revision for all whose Surgical knowledge has lapsed. It is up-to-date, accurate, authoritative and refreshing to read.

W. C. Moffat 
A Nurse's Guide to Anaesthetics, Resuscitation and Intensive Care. Fifth ed. W. NorRis and D. CAMPBELL. Edinburgh and London. Churchill Livingstone. 1972. Pp. ix $+177 . £ 1 \cdot 50$. Ill ustrated. A Nurse's Guide to the X-ray Department. Second ed. M. Goldman. Edinburgh and London. Churchill Livingstone. 1972. Pp. Xv $+85 £ 1 \cdot 00$. Illustrated.

Having read both books I have come to the conclusion that they would be extremely useful to student nurses in training.

Both are brief but comprehensive, well laid out and interesting.

G. A. MANNing

Vector Control in International Health. Various Authors. Geneva. World Health Or ganisation. 1972. Pp. vi + 141. $13 \cdot 20$. Illustrated.

An advantage, though a somewhat dubious one, of insect-borne disease, is that a double-edged attack on their spread can often be attempted, the first to eradicate the disease from the human victim, and the second to control the creature which transmits the disease organism.

International health legislation is aimed at dealing with the human aspect of the export or import of disease, which in itself imposes considerable problems, but clearly it is vitally important to control as well the insect which carries the disease organism. Infected insects could be so easily be carried in the cargoes of ships, in luggage of aircraft, and even on the bodies of healthy passengers. True, the climatic conditions at the destination may not allow the vector to establish itself, but the insect only needs to feed once in its new surroundings to transmit what is often a non-endemic disease in a new country.

The World Health Organisation's publication, Vector Control in International Health, is an invaluable aid in combating the passage of disease vectors at ports and airports. This aspect is discussed in the first five chapters, and 'in transit' control in ships and aircraft is covered in Chapters 4 and 5 respectively. Chapter 2 is especially useful, being a concise description of the vectors themselves, their life-cycles and relevant control methods. Chapter 3 deals with the biology and control of domestic rodents. A valuable annex consists of pictorial keys for the identification of the major animals of public health importance. This is altogether an excellent and most useful publication for all those concerned with the prevention and control of arthropod-borne disease.

N. R. H. BuRress

A Short Textbook of Medicine. Fourth ed. J. C. Houston, C. L. Joiner and J. R. Trounce. London. The English Universities Press Ltd. 1972. P.574. £1·75.

The success of this book reflects the accuracy with which the authors have succeeded in producing an inexpensive, short, yet sound textbook of Medicine. It is aimed primarily to prepare the student during the years leading to a medical degree, but provides many doctors with the opportunity of a quick review of the field of medicine. At a cost of $£ 1 \cdot 75$ it represents value for money.

The concise text will not appeal to all practitioners but follows from the aim of restricting the size of the volume. The main change from the previous edition has been fuller treatment of immunological reactions in clinical medicine.

J. D. CORMACK

Gastro-enterology. An Integrated course. Ed. by I. E. Gillespie and T. J. Thomson. Edinburgh and London. Churchill Livingstone. 1972. Pp. ix $+261 . £ 1 \cdot 50$. Illustrated.

An integrated inter-disciplinary approach to disease is now firmly part of modern medicine and nowhere more necessarily so than in the management of patients with gastro-intestinal disorder.

This paper-back is based on the integrated gastro-enterology course for fourth year students at the University of Glasgow. The list of contributors is impressive and contains many famous names and the text is authorative and up-to-date. The surgical coverage is a little patchy being very full in some sections but less than desirably so in others, although the Editors do point out that more emphasis has been given to those matters whidh the student commonly finds difficult to understand. There are however, no references in the text and no suggestions for further reading.

The book is slightly more impressive than some of its kind due undoubtedly to the inclusion of a large number of photographs of high quality in addition to the line drawings. There is no doubt, however, that it is a very valuable purchase for the undergraduate or for any doctor who wishes painlessly and pleasurably to review his knowledge in this vast field.

W. C. Moffat

Manson's Tropical Diseases. Seventeenth ed. Ed. by C. Wilcocks and P. E. C. Manson-BAHR. London. Bailliere Tindall. 1972. Pp. xiii $+1142 . £ 10 \cdot 00$. Illustrated.

This new seventeenth edition of Manson's Tropical Diseases edited by Dr. Wilcocks and Dr. Manson-Bahr retains its old format. It is comprehensive in its coverage of tropical disease and has special sections on tropical ophthalmology, protozooology, helminthology and entomology. A new and useful section on drugs has been added. Recent developments in tropical medicine are adequately covered and the tables of references provided. The illustrations, many of which are new, are particularly good.

This book maintains its position as the Standard British Work on Tropical Medicine.

W. O'BRIEN

Polyglot Medical Questionnaire. Second ed. S. C. PARry. London. W. Heinemann Medical Books Ltd. 1972. Pp. vii $+88 . £ 5 \cdot 00$.

This is a specialised reference book now in its second edition, which offers a selection of one hundred and ninety-three questions, phrases and words in twenty-seven languages. Its aim is to permit the doctor to communicate with a patient when no spoken language is of help. It is not difficult to find the corresponding questions in the different language. The questions are phrased to demand "yes ", "no " or numerical answers. 